\title{
PENGAYAAN ASAM LEMAK OMEGA-3 DARI MINYAK IKAN TUNA (Thunnus sp.) DI SULAWESI UTARA
}

\author{
Ni Made Megasanti ${ }^{1}$, Julius Pontoh ${ }^{1}$, Harry S. J. Koleangan ${ }^{1}$ \\ ${ }^{1}$ Program Studi Kimia, Fakultas Matematika dan Ilmu Pengetahuan Alam \\ Universitas Sam Ratulangi Manado
}

\begin{abstract}
ABSTRAK
Telah dilakukan penelitian mengenai pengayaan kandungan asam lemak omega-3 dari minyak ikan tuna (thunnus sp) di Sulawesi utara dengan metode kristalisasi dengan urea.Penelitian telah dilakukan dengan kristalisasi urea pada dua suhu berbeda dan waktu kristalisasi, selanjutnya hasil kristalisasi dianalisa dengan mengunakan analisis kromatografi lapis tipis dan analisis kromatografi gas. Hasil penelitian menunjukan bahwa fraksi etil ester asam lemak dan urea meningkatkan kandungan asam lemak omega-3 pada minyak ikan. Kandungan asam lemak tak jenuh majemuk seperti kandungan DHA dan EPA meningkat dan mendapatkan hasil terbaik pada suhu $1^{\circ} \mathrm{C}$ dengan waktu 24 jam. Sesudah kristalisasi urea asam lemak meningkat, asam lemak DHA pada kepalaikan tuna dari 33,00\% menjadi 39,09\%.Asam lemak EPA pada kepala tuna dari $1,26 \%$ menjadi $11,16 \%$.
\end{abstract}

Kata kunci: urea pekat, asam lemak omega-3, kromatografi gas

\section{ABSTRACT}

Research on the enrichment of omega-3 fatty acid content from tuna (thunnus sp) oil in North Sulawesi by crystallization method with urea has been carried out.Research has been carried out with urea crystallization at two different temperatures and crystallization time, then the crystallization results were analyzed using thin layer chromatography analysis and gas chromatography analysis. The results showed that the ethyl ester fatty acid fraction and urea increased the omega-3 fatty acid content in fish oil. The content of compound unsaturated fatty acids such as DHA and EPA content increases and gets the best results at $1^{\circ} \mathrm{C}$ in 24 hours.After the crystallization of fatty acid urea increased, the fatty acid DHA in tuna fish heads from $33.00 \%$ to $39.09 \%$ EPA fatty acids in tuna heads from $1.26 \%$ to $11.16 \%$.

Keywords: concentrated urea, omega-3 fatty acids, gas chromatography.

\section{PENDAHULUAN}

Laut merupakan salah satu sumber kekayaan alam Indonesia. Produksi ikan Indonesia tercatat 6.603.63ton pada tahun 2019 dan Sulawesi Utara sebagai penyumbang dari data di atas tercatat sebesar 393.448 ton. Jenis ikan yang ada di Sulawesi Utara di antaranya ikan pelagis dan ikan karang (Dotulong dkk., 2018). Ikan tuna (Thunnus $s p$ ) ciri dari ikan tuna adalah mempunyai kecepatan berenang mencapai 50 $\mathrm{km} / \mathrm{jam}$, ukurannya raksasa, dan mempunyai panjang ratarata lebih dari 1,5 meter serta mempunyai berat sampai ratusan kilo. Ikan tuna termasuk dalam keluarga Scrombidae, terdiri dari, tuna besar (yellowfin tuna, bigeye, southern bluefin tuna, albacore) dan ikan mirip tuna (tuna-like

\footnotetext{
Korespondensi:

Telepon: +62 822-9274-6061

Email: megasanti44@gmail.com

DOI: https://doi.org/10.35799/cp.13.2.2020.31458
}

species), yaitu marlin, sailfish, dan swordfish (Kuncoro \& Wiharto, 2009)

Asam lemak dibedakan atas asam lemak jenuh dan tak jenuh. Asam lemak tak jenuh dibedakan atas asam lemak tak jenuh tunggal (monounsaturated fatty acid) dan asam lemak tak jenuh majemuk (polyunsaturated fatty acid). Lemak dari ikan laut mengandung polyunsaturated, yang sebagian mengandung omega-3. (Wang, 1990). Asam-asam lemak ini mempunyai fungsi biologis yang dapat meningkatkan kesehatan otak, penglihatan (mata) dan mencegah penyakit pembuluh darah (aterosklerosis) (Kaur dkk., 2012).

Berdasarkan struktur kimianya, asam lemak dibedakan menjadi asam lemak jenuh (saturated fatty acid) yaitu asam lemak yang tidak memiliki ikatan rangkap, sedangkan asam lemak yang 
memiliki ikatan rangkap disebut sebagai asam lemak tidak jenuh (unsaturated fatty acids), yang dibedakan menjadi mono unsaturated fatty acid (MUFA), memiliki satu ikatan rangkap, dan poly unsaturated fatty acids (PUFA) dengan dua atau lebih ikatan rangkap (Sartika, 2008).

Beberapa cara untuk mendapatkan asam lemak kaya omega-3 yaitu cara kromatografi, destilasi, kristalisasi dalam suhu rendah dan urea kompleks. Berikut adalah kelebihan dari metodemetode yang telah disebutkan dalam memperoleh asam lemak kaya omega-3. Metode kromatografi dapat memisahkan asam lemak berdasarkan tingat kejenuhannya dengan mengunakan pelarut yang sesuai (Brown dkk., 1955). metode destilasi dilakukan pemisahan secara parsial dari campuran etilester yang tergantung pada tingkat titik didih (Brown dkk., 1955).

\section{BAHAN DAN METODE}

\section{Alat dan bahan}

Alat-alat yang akan digunakan yaitu, pisau, talenan, kompor gas, panci stenlis steel, botol trasparan $600 \mathrm{~mL}$, pipet tetes, tabung reaksi, sentrifuge, botol vial, timbangan analitik, alumunium foil, gelas ukur, labu takar, stirrer, dan seperangkat alat kromatografi gas.

Bahan-bahan yang akan di gunakan yaitu hasil ekstraksi dan derivatisasi pada penelitian sebelumnya. Bahan kimia yang digunakan adalah etanol (P.A), tisu, kertas saring, seperangkat alat lapisan tipis gel silika, natrium hindroksida $(\mathrm{NaOH})$ (P.A), potassium hidroksida $(\mathrm{KOH})$ (P.A), larutan Urea pekat (P.A), aquades, asam asetat (P.A), aseton (P.A), n-heksana (P.A), klorofom (P.A), dan asam fosfomolibdat (P.A).

Isolasi mengunakan pelarut Urea pekat (Bispo dkk., 2014)

Sampel kepala (cakalang, tuna dan tindarung) di ekstraksi menggunakan metode wet rendering menghasilkan minyak ikan. Sampel minyak ikan di transesterifikasi dengan cara penambahan katalis $2 \% \mathrm{KOH}(0,2 \mathrm{~g} / 10 \mathrm{~mL}$ etanol) dan dipanaskan pada suhu $65^{\circ} \mathrm{C}-70^{\circ} \mathrm{C}$ selama 2 jam. Sampel tranesterifikasi sampel tranesterifikasi diambil sebanyak $6 \mathrm{~g}$, kemudian di tambahkan larutan urea pekat $(18 \mathrm{~g} / 100 \mathrm{~mL}$ etonol) dengan perbandingan 1:3 (1 bagian sampel dan 3 bagian larutan urea pekat) (b/b). Campuran diaduk dengan cara dikocok sampai bercampur secara homogen. Setelah homogen, campuran dipanaskan pada suhu $65^{\circ} \mathrm{C}$ sampai larutan berubah menjadi bening. Diamkan dalam suhu masing-masing $1^{\circ} \mathrm{C}$ dan $-10^{\circ} \mathrm{C}$. Sampel sebanyak $2 \mathrm{~mL}$ di ambil setelah 24 jam dan 48 jam untuk dianalisa selanjutnya. Fraksi kristal dan cairan dipisahkan dengan cara disaring. Fraksi cair dianalisa dengan TLC dan Gas Kromatografi.

\section{Analisis kromatografi lapis tipis}

Pelat silica gel $60 \mathrm{~F}-254$ berukuran $5 \times 10$ $\mathrm{cm}$ dengan ketebalan 0,25 mm. Diaktifkan dengan cara dipanaskan pada suhu $100^{\circ} \mathrm{C}$ selama 1 jam. Sampel dilarutkan dalam pelarut klorofrom dengan konsentrasi $10 \mathrm{mg} / \mathrm{mL}$. sebanyak $10-\mu \mathrm{L}$ sampel ditotolkan dengan pipa kapiler di setiap titik KLT. Cairan pengembang terdiri dari klorofrom, asam asetat, dan aseton $(43,15 \mathrm{~mL}, 0,1$ $\mathrm{mL}$, dan 1,9 mL). Masukan plat silica gel kedalam bejana yang berisi larutan pengembang diamkan hingga larutan pengembang merambat sampai pada batas atas selama 15 menit. Piringan disemprot dengan $10 \%$ asam fosfomolibdat dalam etanol dan dikeringkan dalam oven pada suhu $120^{\circ} \mathrm{C}$ selama 10 menit. Identifikasi fraksi-fraksi lipida dalam sampel ditentukan dengan membandingkan hasil standart faraksi-fraksi lipida oleh (Magallanesdkk., 2018)

\section{Analisis kromatografi gas}

Analisis kromatografi gas dilakukan menggunakan Shimadzu Gas Chromatography (GC-2014) dengan Flame Ionization Detector (FID) dan Capillary Silica Fuse Column (RtFAME) dengan panjang $30 \mathrm{~m}$, diameter $0,25 \mathrm{~mm}$, ketebalan film $0,25 \mu \mathrm{m}$. Suhu kolom dari $120^{\circ} \mathrm{C}$ selama 7 menit lalu meningkat sampai $250^{\circ} \mathrm{C}$ dengan jalannya suhu $10^{\circ} \mathrm{C} /$ menit dan selama 26 menit suhu konstan sebesar $250^{\circ} \mathrm{C}$. Suhu injeksi dipanaskan pada $260^{\circ} \mathrm{C}$, dilengkapi dengan injector split-pisah dengan 1/10 dan tekanan gas pembawa helium diatur pada $75 \mathrm{kPa}$. Sebelum sampel diinjeksi $200 \mathrm{~mL} / \mathrm{g}$ sampel ditambahkan $1 \mathrm{~mL}$ n-heksan. Satu mikroliter sampel dimasukkan ke tempat injeksi. (Pontoh, 2016).

\section{Penentuan kandungan asam lemak}

Waktu retensi asam-asam lemak pada minyak ikan ditentukan berdasarkan waktu retensi asam-asam lemak Supelco 37 Component FAME Mix (standar) dengan beberapa modifikasi. 
Menurut Khan (2013) Komposisi asam-asam lemak ditentukan berdasarkan jumlah luas puncak etil ester urea pekat asam-asam lemak dibagi total luas puncak dikali 100\%.

Rumus persen luas puncak:

$$
\text { Persen luas puncak }
$$

$\frac{\text { Luas puncak etil ester asam-asam lemak }}{\text { Total luas puncak asam-asam lemak }} \times 100 \%$

\section{HASIL DAN PEMBAHASAN}

\section{Kromatografi lapisan tipis}

Tujuan menggunakan kromatografi lapis tipis dalam penelitian ini untuk melihat metil ester asam lemak yang terbentuk. Analisa menggunakan kromatografi lapisan tipis (KLT) untuk menentukan etil ester asam lemak, mengetahui kelas lemak yang telah terbentuk dan hasil gliserol yang tidak teresterifikasi(Sapta \& Cahyani, 2014).

Komponen lipida dalam sampel ditentukan berdasarkan pada standard KLT lipida standard (Rodrigues dkk., 2009).

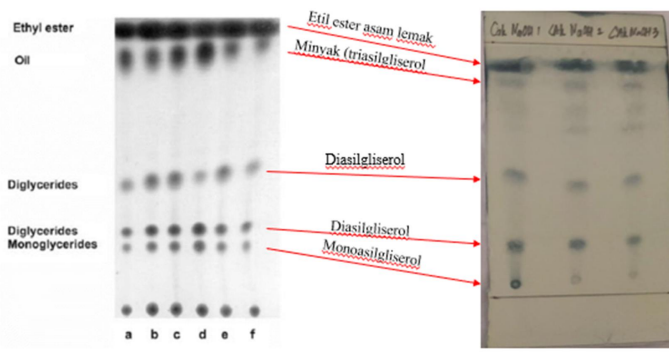

Sebelum ditambahkan urea

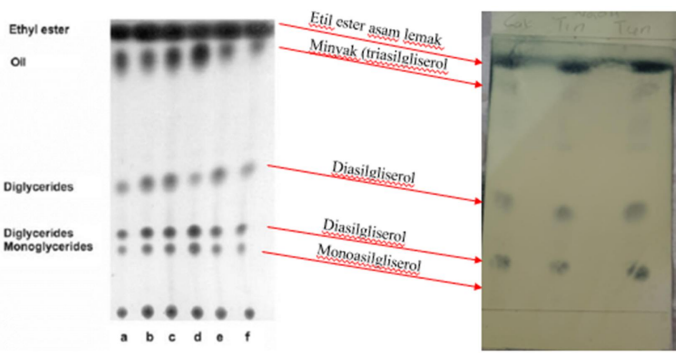

Sesudah ditambahkan urea

Gambar 1.Perbandingan hasil KLT sesudah dan

\section{sebelum ditambahkan urea}

Dari gambar 9 dapat dilihat pada perlakuan sebelum dan sesudah penambahan urea dalam fraksi minyak untuk sebelum penambahan urea terlihat lebih pekat dan untuk yang ditambahkan urea terlihat berkurang. Pada kedua perlakuan terdapat fraksi diasilgliserol yang terbagi menjadi dua senyawa yang seharusnya ada tiga senyawa tetapi karena jenis senyawa yang sama sehingga satu senyawanya tertumpuk dengan yang lain sehingga terbaca hanya dua senyawa saja. Perlakuan sebelum ditambahkan urea di mana fraksi monogliserol sangat pekat dan dalam perlakuan sesudah ditambahkan urea fraksi monogliserol berkurang, karena fraksi monogliserol sudah terperangkap dalam kristal urea sehingga terlihat berkurang dalam perlakuan plat silika gel yang ditambahkan urea.

Platsilika gel pada gambar 1 bagian bawah mengandung senyawa polar. Untuk bagian atas yang warnanya lebih pekat mengandung senyawa nonpolar. Pengaruh waktu rambat cepat dikarenakan cairan pengembang yang digunakan bersifat polar. Senyawa polar dapat merambat dengan cepat dalam fase diam (platsilika gel) (Rodrigues dkk., 2009).

Tabel 1 menunjukan persen dari gambar 9 . Pada tabel 1 menunjukan etil ester asam lemak sesudah di tambahakan urea menunjukan hasil lebih tinggi. Pada persen minyak (triasil gliserol) juga mendapatkan hasil lebih rendah dari sampel sebelum ditambahkan urea. Pada diasil gliserol mendapatkan hasil yang hampir mirip. Pada monoasil gliserol sampel yang sesudah ditambahkan urea tidak terlihat pada plat silica.

Tabel 2. Persen Kandungan komponen lipida dalam sampel sesudah isolasi

\begin{tabular}{|c|c|c|}
\hline \multirow{2}{*}{} & \multicolumn{2}{|c|}{ Tuna } \\
\cline { 2 - 3 } & Sebelum & Sesudah \\
\hline Etil ester asam lemak & 84 & 90 \\
\hline Minyak (Triasil gliserol) & 3 & 1 \\
\hline Diasil gliserol & 4 & 5 \\
\hline Diasil gliserol & 5 & 3 \\
\hline Monoasil gliserol & 4 & - \\
\hline
\end{tabular}




\section{Kromatografi Gas}

\section{Penentuan asam-asam lemak}

Untuk mengetahui retention time etil-etil ester, maka dilakukan analisa terhadap standar Supelco 37 component FAME mix yang hasilnya terlihat pada gambar 11. Hasil kromatogram terpisah dengan baik dan digunakan sebagai panduan dalam menentukan metil ester yang terdapat dalam sampel. Kromatogram gambar 12 menunjukkan 35 puncak yang muncul dikarenakan asam-asam lemak yang lain tertindih satu sama lain dalam satu puncak sehingga terbaca hanyalah 35 puncak saja. Hal ini juga dilaporkan oleh (Khan, 2013).

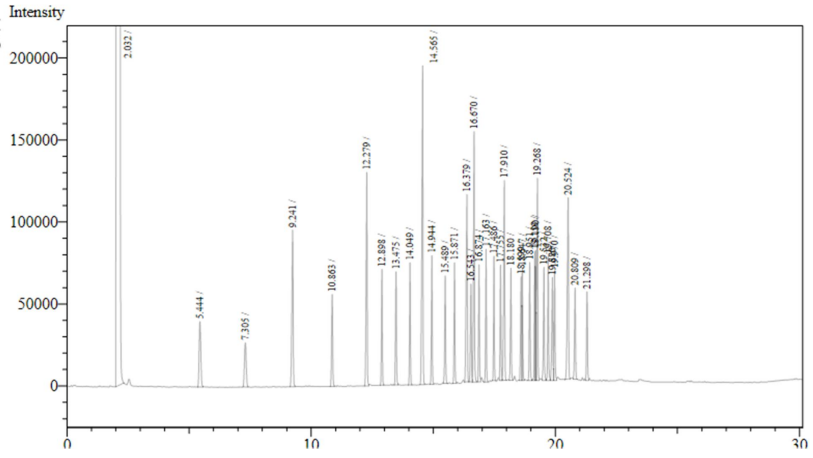

Gambar 2. Kromatogram Larutan Standard Supelco FAME Mix Kromatografi Gas

Hasil analisa dari penambahan larutan urea pekat kedalam sampel esterifikasi. Ditunjukan pada gambar 12 dimana kromatogram menunjukan puncak-puncak yang hampir mirip dengan standard dan puncak yang terbaca. Waktu retensi pada standard dan sampel menunjukan senyawa yang berbeda pada gambar 2 dan gambar 3. Hal ini disebabkan karena standard dalam bentuk metilester asam lemak dan sampel dalam bentuk etilester asam lemak yang telah dikonfirmasi melalui kromatografi GC-MS.

Pengkristalan pada suhu $1^{\circ} \mathrm{C}$ dalam sampel esterifikasi (gambar 3) tidak banyak perbedaan antara puncak-puncaknya. Walaupun terlihat hampir sama perbedaan antara kepala ikan cakalang, tuna dan tindarung. Hasil esterifikasi di mana puncak yang terlihat atau luas area dan waktunya berbeda-beda. Terlihat pada kromatogram dimana semua mempunyai puncakpuncak yang hampir mirip dengan standard. Hasil kromatogram menunjukkan bahwa puncak-puncak yang muncul terpisah dengan baik sehingga dapat digunakan sebagai panduan untuk menentukan asam-asam lemak apa saja yang terdapat dalam sampel. Hal ini juga telah dilaporkan oleh Khan (2013) yang menggunakan kolom dan standar yang sama.

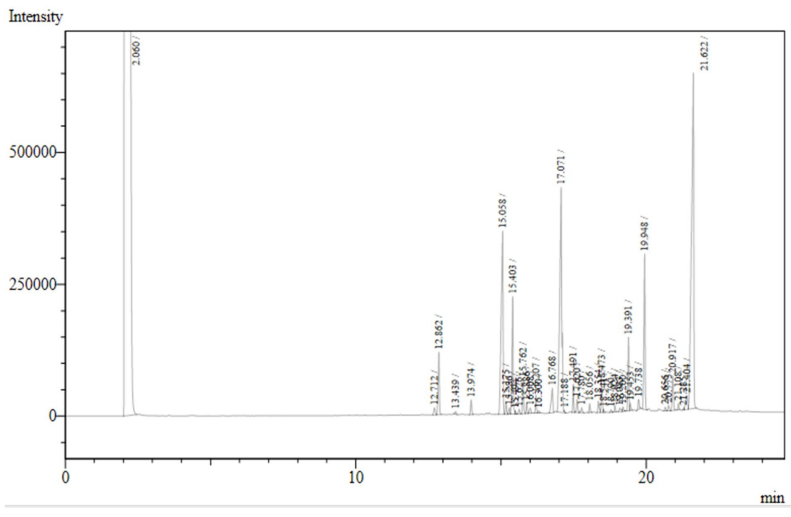

Gambar 3. Kromatogram 24 jam Tuna $1{ }^{\circ} \mathrm{C}$

\section{Analisis profil asam lemak}

Tabel 4 menunjukan asam lemak dalam sampel sebelum dikristalisasi urea dan sesudah dikristalisasi urea. Pada sampel sebelum kristalisasi didapatkan hasil asam lemak tinggi pada kepala ikan tuna mengandung asam lemak tinggi yaitu DHA $(33.00 \%)$, palmitat $(19,24 \%)$, dan linolaidat $(17,32 \%)$, oleat $(5,00 \%)$, dokosadionat $(7,28 \%)$, palmitoleat $(4,73 \%)$, dan EPA $(1,26 \%)$. Pada peneltian sebeumnya (Mohanty et al., 2016) badan ikan tuna mengandung DHA $(8,3 \%)$, palmitat $(31,6 \%)$, oleat $(13,8 \%)$, dan EPA $(3,0 \%)$. Dan penelitian sebelumnya Estiasih Teti (2009), di mana badan ikan tuna mengandung DHA sebesar $(27,76 \%)$ dan EPA sebesar (8,68\%). pada hasil penelitian ini didapatkan hasil asam lemak EPA lebih rendah dari penelitian sebelumnya dan asam lemak DHA lebih tinggi dari hasil penelitian sebelumnya.

Dari data pada table 4 menunjukan bahwa kristalisasi urea menyebabkan peningkatan kandungan asam-asam lemak tidak jenuh majemuk seperti DHA, EPA dan Linolelaidat, sedangkan asam lemak jenuh dan tidak jenuh tunggal menurun seperti asam palmitat dan oleat. Kepala ikan tuna meningkat pada asam lemak miristat $(8,41 \%)$, dan EPA $(8,21 \%)$. Menurun pada asam lemak DHA $(32,09 \%)$, palmitat $(13,21 \%)$, oleat $(1,55 \%)$, linolelaidat $(16,25 \%)$. penelitian sebelumnya Estiasih Teti (2009), di mana badan ikan tuna mengandung asam lemak 
EPA sebesar (14,39\%) dan DHA sebesar (64,59\%) kandungan asam lemak EPAdan DHA pada penelitian sebelumnya mendapatkan hasil yang lebih tinggi dibandingkan pada penelitian ini hal ini dikarenakan menggunakan metode yang berbeda.

Suhu kristalisasi pada tabel 4 memberikan pengaruh pda komposisi asam lemak dari minyak ikan Pada suhu $1^{\circ} \mathrm{C}$ dan $-10^{\circ} \mathrm{C}$ hampir semua hasil yang didapatkan meningkat hanya ada beberapa saja yang hasilnya menurun. Kepala ikan tuna meningkat kandungan asam lemak EPA $(7,23 \%)$, dan miristat $(8,41 \%)$. Menurun pada asam lemak palmitat (13,21\%), DHA (32,09\%), oleat $(1,55 \%)$, dan linolelaidat $(16,52 \%)$. Pada kepala ikan tuna suhu $-10^{\circ} \mathrm{C}$ asam lemak miristat $(8,80 \%)$, dan EPA $(7,62 \%)$. Menurun pada asam lemak DHA $(31,31 \%)$, palmitat $(16,32 \%)$, oleat $(3,51 \%)$, dan linolaidat $(12,01 \%)$.

Hal ini dipengaruhi oleh suhu yang digunakan suhu yang $1{ }^{\circ} \mathrm{C}$ urea dalam sampel mengkristal perlahan berbeda dengan suhu $-10^{\circ} \mathrm{C}$ yang pengkristalan dalam sampel terjadi pembekuan sangat cepat sehingga menyebabkan hasil asam lemak majemuk banyak terjebak dalam tetragonal urea sehingga hasil didapatkan berkurang.

Perbandingan waktu pengkristalan pada 24 jam dan 48 jam. Pada 24 jam pengkristalan sampel kepala ikan tuna meningkat kandungan asam lemak EPA $(7,23 \%)$, dan miristat $(8,41 \%)$. Menurun pada asam lemak palmitat $(13,21 \%)$, DHA $(32,09 \%)$, oleat $(1,55 \%)$, dan linolelaidat (16,52\%). Kandungan asam lemak pada 48 jam lebih rendah dibandingkan dengan kandungan asam lemak pada 24 jam. Karena pada 24 jam pengambilan sampel lebih banyak asam lemak yang terambil. Pada 48 jam asam lemak yang diambil merupakan asam lemak sisa dari pengambilan pada 24 jam sehingga hasil pada 48 jam mendapatkan kandungan asam lemak lebih rendah.

Tabel 3 Kandungan Asam Lemak pada sampel sebelum dan sesudah pengkristalan 24 Jam dan 48 jam dengan suhu $1^{\circ} \mathrm{C}$ dan $-10^{\circ} \mathrm{C}$ Pengkristalan Urea.

\begin{tabular}{|c|c|c|c|c|c|c|}
\hline \multirow{2}{*}{\multicolumn{2}{|c|}{ Asam Lemak }} & $\begin{array}{c}\text { sebelum } \\
\text { dikristalisasi dengan } \\
\text { urea }\end{array}$ & $\begin{array}{c}24 \text { jam suhu } \\
1^{\circ} \mathrm{C}\end{array}$ & $\begin{array}{c}48 \text { jam suhu } \\
1^{\circ} \mathrm{C}\end{array}$ & $\begin{array}{c}24 \text { jam suhu - } \\
10^{\circ} \mathrm{C}\end{array}$ & $\begin{array}{c}48 \text { jam } \\
\text { suhu }-10^{\circ} \mathrm{C}\end{array}$ \\
\hline & & Tuna & Tuna & Tuna & Tuna & Tuna \\
\hline Miristat & $\mathrm{C}-14$ & 2,82 & 8,41 & 2,96 & 8,80 & 3,20 \\
\hline Miristoleat & C-14:1 & & 3,00 & & & \\
\hline Pentadekanoat & $\mathrm{C}-15$ & 0,78 & & & & \\
\hline Palmitat & C-16 & 19,24 & 13,21 & 12,25 & 16,32 & 12,00 \\
\hline Palmitoleat & C-16:1 & 4,73 & & & & \\
\hline Heptadekanoat & $\mathrm{C}-17$ & 1,27 & & & & \\
\hline Heptadenoat & $\mathrm{C}-17: 1$ & 0,80 & 5,21 & 5,13 & 5,27 & 5,10 \\
\hline Stearat & $\mathrm{C}-18$ & 0,93 & & & & \\
\hline Elaidat & C-18:1 Trans & 0,35 & 3,91 & 1,22 & 2,12 & 4,56 \\
\hline Oleat & C-18:1 Cis & 5,00 & 1,55 & 1,16 & 3,51 & 1,70 \\
\hline Linolelaidat & C-18:2 Trans & 17,32 & 16,52 & 18,08 & 12,01 & 16,33 \\
\hline Linoleat & C-18:2 Cis & 1,01 & 1,41 & 1,25 & 1,42 & 1,25 \\
\hline Arakidat & $\mathrm{C}-20$ & 0,60 & & & & \\
\hline $\mathrm{\gamma}$-Linolenat & C-18:3 Cis-6 & & & & 2,49 & \\
\hline Eikosanoat & $\mathrm{C}-21 \mathrm{Cis}$ & 0,44 & 1,03 & 1,03 & 1,40 & 1,19 \\
\hline$\alpha$-Linolenat & C-18:3 Cis-9 & 1,77 & & & & \\
\hline Eikosatrienoat & $\begin{array}{c}\mathrm{C}-20: 3 \mathrm{Cis} / \\
\mathrm{C}-22: 1\end{array}$ & & 1,14 & 1,73 & 1,24 & 1,97 \\
\hline Arakidonat & C-20:4 & 0,39 & 2,44 & 2,00 & 2,68 & 3,00 \\
\hline Trioksanoat & $\mathrm{C}-23$ & 0,36 & & & & \\
\hline Dokosadienoat & C-22:2 & 7,28 & & & & \\
\hline EPA & C-20:5 EPA & 1,26 & 7,23 & 11,16 & 7,62 & 9,45 \\
\hline \multirow[t]{2}{*}{ Nervonat } & C-24:1 & 0,66 & 1,73 & 2,29 & 2,12 & 2,56 \\
\hline & & & 1,10 & & 1,70 & \\
\hline DHA & C-22:6 DHA & 33,00 & 32,09 & 39,73 & 31,31 & 37,68 \\
\hline \multicolumn{2}{|c|}{ Jumlah } & 100 & 100 & 100 & 100 & 100 \\
\hline
\end{tabular}




\section{KESIMPULAN}

Peningkatan kandungan asam lemak omega-3 dengan cara kristalisasi urea meningkatkan kandungan asam lemak tak jenuh majemuk seperti pada EPA dan DHA. Kandungan asam lemak tak jenuh tunggal menurun seperti pada palmitat dan oleat. Untuk suhu pengkristalan $1{ }^{\circ} \mathrm{C}$ mendapatkan hasil rata-rata tinggi dan waktu 24 jam mendapatkan hasil rata-rata tinggi.

Kandungan asam lemak omega-3 utama sesudah kristalisasi urea dari kepala ikan cakalang, tuna dan tindarung secara berterut-turut adalah DHA, EPA, palmitat, dan linolelaidat.

\section{DAFTAR PUSTAKA}

Brown, L. B. \& D. X. Klob. 1955. Application Of Low Temperature Crystallization In Separation Of Fatty Acids And Their Compounds. Progress in Lipid Research. 3(1), 57- 94.

Estiasih Teti 2009. Optimizing Conditions for the Purification of Omega-3 Fatty Acids from By-product of Tuna (Thunnussp) Meal Processing by Urea Crystallization. Jurnal teknol danindustri pangan. 2(20), 137-138

Eko, B. K. \& F. E. A. Wiharto. 2009. Ensiklopedia Populer Ikan Air Laut. Yogyakarta: Lily Publisher.
Kaur, N., V. Chugh. \& A. K. Gupta. 2012. Essential Fatty Acids As Functional Components Of Foods A Review. Journal Food Science Technology. 51(10), 2289-2303.

Khan, I. K. 2013. A GC-FID Method for The Comparison of Acid and Base-Catalyzed Derivatization of Fatty Acids to Fames in Three Edible Oils. Runcorn UK: Thermo fisher Scientific.

Magallanes, L. M., Lorena V. T., \& Nelson R. G. 2018.Highly Concentrated Omega-3 Fatty Acid Ethyl Ester by Urea Complexation and Molecular Distillation.Journal of the science of food and argriculture. 2(4), 4-6

Pontoh, J. 2016. Gas Chromatographic Analysis of Medium Chain Fatty Acids in Coconut Oil. Journal of Pure and Applied Chemistry Research. 5(3), 157 - 161.

Pontoh, J. 2019. Extracion And Charactrizaiton Of Fish Oil From Various Parts Of Snakehead Fish (Chana striata). International Journal of ChemTech Research. 12(1), 323-328

Sartika, R. A. D. 2008. Pengaruh Asam Lemak Jenuh, Tidak Jenuh dan Asam Lemak Trans Terhadap Kesehatan. Jurnal Kesehatan Masyarakat Nasional. 2(4), 154-160.

Sapta, R \& D. Cahyani. 2014. Isolasi dan Identifikasi Monoasilgriserol Omega-3 (MONOESTER OMEGA-3).E-jurnal Agroindustri Indonesia.2(1), 12-15. 